\title{
EPIDEMIOLOGIA DE LA INFECCION POR EL VIRUS DE LA HEPATITIS B EN DOS POBLACIONES DEL DEPARTAMENTO DEL MAGDALENA
}

FERNANDO DE LA HOZ (1), MANCEL E. MARTINEZ D. (2), MIRITH VASQUEZ (3), ALEJANDRO ROSSI C. (4), CRAIG SHAPIRO (5), ALBERTO ALZATE (6)

Durante 1989 se llevó a cabo una encuesta de seroprevalencia de infección por el virus de la hepatitis $B$ (VHB) en dos poblaciones del departamento del Magdalena (costa norte de Colombia): Cerro Azul y Varela, las cuales presentaban historia reciente de casos de hepatitis fulminante (HF) causada por co y sobre infección del virus de la hepatitis Delta (VHD) en portadores del antígeno de superficie del VHB (HBsAg).

De acuerdo con los resultados obtenidos, en la población con mayor número de casos fulminantes, Cerro Azul,la infección por VHB empieza desde la infancia temprana, probablemente por transmisión horizontal y alrededor de los 15 años, ya la mitad de la población ha sido infectada por VHB. En ella los principales factores asociados con la infección fueron: la carencia de un sistema de disposición de excretas, el hacinamiento y el antecedente de algún familiar muerto por Hepatitis.

En la segunda población, Varela, menos afectada por la hepatitis fulminante, la infección por VHB ocurre a edades más tardias: desde los 15 años en adelante, y alrededor de los 30 años, la mitad de la población ha sido infectada por este virus. En ella los factores que hallamos asociados a la infección por VHB son; el sexo masculino, la carencia de un sistema de eliminación de excretas, el antecedente de transfusión sanguínea y la aplicación de medicamentos parenterales ambulatorios.

PALABRAS CLAVES:

Hepatitis B.

Factores de riesgo.

Hepatitis Fulminante.

Odds Ratio.
ABREVIATURAS USADAS:

$$
\begin{array}{ll}
\text { OR } & =\text { Odds ratio, Riesgo Relativo } \\
\text { VHB } & \pm \text { Virus de la Hepatitis B } \\
\text { VHD } & \pm \text { Virus de la Hepatitis Delta } \\
\text { HBsAg } & \pm \text { Antígeno de Superficie del VHB }
\end{array}
$$

Anti-HBc \pm Anticuerpo contra el Antígeno Core del VHB

\footnotetext{
(1) Investigador Científico, Grupo Vigilancia Epidemiológica, INS.

(2) Coordinador Vigilancia Epidemiológica, INS.

(3) Enfermera Servicio de Salud del Magdalena.

(4) Programa Hepatitis B, INS.

(5) CDC Atlanta, Georgia, EE. UU.

(6) Universidad del Valle.
} 


\section{INTRODUCCION}

En el piedemonte occidental de la Sierra Nevada de Santa Marta, Colombia, hay varias poblaciones afectadas periódicamente por brotes de hepatitis fulminante (HF) la cual es causada por sobre infección o coinfección de los virus de la Hepatitis Delta (VHD) y de la Hepatitis B (VHB) $(1,2,3,4,6,19,20)$.

En dos de estas poblaciones, se llevó a cabo un estudio de seroprevalencia de la infección por VHB, auspiciada por OPS, CDC, INS, y el Servicio Seccional de Salud del Magdalena.

El objetivo era determinar los patrones de transmisión del VHB en estos lugares y hallar algunos factores asociados con la infección por este virus.

La localidad de Varela, está localizada en la zona bananera del departamento del Magdalena, a 50 metros sobre el nivel del mar y a 45 kilometros de Santa Marta, al momento de la encuesta tenía alrededor de 1200 habitantes. Cerro Azul está localizada a 1500 metros de altitud en la Sierra Nevada, a 100 kilometros aproximadamente de Varela y su población de 468 habitantes es dispersa. Las dos poblaciones difieren en su origen, ya que los pobladores de Varela son en su mayoría del tipo negroide predominante en la costa caribe colombiana, mientras que los de Cerro Azul provienen de la región andina y son en su mayoría de tipo caucasoide.

Cerro Azul ha sido la población mas afectada por la $\mathrm{HF}$ con 15 casos confirmados desde 1989 , mientras en Varela solo se han presentado 3 casos en ese mismo lapso. Ambos comparten una carencia total de servicios públicos, tales como acueducto, alcantarillado y atención médica regular.

\section{MATERIALES Y METODOS}

La información epidemiológica se recogió por medio de encuesta, aplicada casa por casa.

A todos los habitantes que aceptaron participar en el estudio, con excepción de los recién nacidos, le fueron extraídos $10 \mathrm{ml}$ de sangre, la cual, una vez centrifugada, rotulada y refrigerada fue enviada al laboratorio de hepatitis del Centro para el Control de Enfermedades (CDC), Atlanta, Georgia, Estados
Unidos. Allí se estudiaron anticuerpos contra el antígeno central del VHB ( anti- HBc). Se eligió este marcador por ser el que permanece detectable mayor tiempo, en las personas que han sido infectadas por VHB. Para la detección se usó la prueba de radio-inmunoanálisis (RIA).

Fueron consideradas infectadas por VBH, aquellas personas que presentaron positividad para el anti-HBc, con excepción de los menores de doce meses, ya que en ellos, este anticuerpo puede ser adquirido pasivamente de la madre.

Las personas que fueron negativas para el anti$\mathrm{HBc}$, se consideraron susceptibles a la infección por VHB y se les incluyó en un programa de vacunación contra VHB, que realiza en la región el INS, la OPS, CDC y el Servicio de Salud del Magdalena.

El análisis para explorar factores de riesgo individuales, se llevó a cabo comparando los infectados con los susceptibles, respecto a las variables recogidas en la encuesta. Las variables elegidas fueron: edad, sexo, hacinamiento, calidad de vivienda, disposición de excretas, historia personal de hepatitis vírica, número de compañeros sexuales, estado civil, antecedentes de transfusión sanguínea, lugar donde realizó la transfusión, número de inyecciones aplicadas en el año anterior, y antecedente familiar de muerte o enfermedad crónica por Hepatitis.

Para el análisis se utilizaron tablas tetracóricas, obteniéndose el Odds Ratio (OR) para cada variable y los intervalos de confianza (IC) del $95 \%$.

La significancia de estas relaciones se examinó con la prueba de chi cuadrado a un nivel crítico de 0.05. El test exacto de Fisher se usó cuando fue requerido.

Se practicó análisis estratificado por edad y sexo para cada variable, analizándose por el método de Mantel y Haentzel, OR M-H, con el fin de eliminar posibles fuentes de confusión. (11).

\section{RESULTADOS}

En Varela se encuestaron 686 personas y en Cerro Azul 405, la prevalencia total de infección por VHB era del $29 \%$ en Varela y del $75 \%$ en Cerro Azul. Tabla 1. 
TABLA 1

PREVALENCIA DE-INFECCION POR VHB EN AMBAS POBLACIONES

\begin{tabular}{|c|c|c|c|c|c|c|}
\hline \multicolumn{4}{|c|}{ VARELA } & \multicolumn{3}{|c|}{ CERRO AZUL } \\
\hline & Total & Infec- & $(\%)$ & Total & Infecta- & $\%$ \\
\hline Hombres & 357 & 90 & 25 & 238 & 180 & 76 \\
\hline Mujeres & 309 & 107 & 26 & 166 & 125 & 75 \\
\hline \multicolumn{7}{|l|}{ EDAD } \\
\hline $0-4 \mathrm{~A}$. & 232 & 7 & 3 & 56 & 30 & 53 \\
\hline $5-14 \mathrm{~A}$. & 269 & 21 & 8 & 162 & 110 & 68 \\
\hline $15-24 \mathrm{~A}$. & 111 & 54 & 49 & 68 & 57 & 84 \\
\hline $25-44 \mathrm{~A}$. & 118 & 79 & 67 & 91 & 81 & 89 \\
\hline$>-44 \mathrm{~A}$ & 43 & 36 & 84 & 28 & 27 & 96 \\
\hline Total & 686 & 197 & 29 & 405 & 305 & 75 \\
\hline
\end{tabular}

La tabla 2 muestra la distribución de algunos factores de riesgo en las dos poblaciones. La proporción de personas con antecedente familiar de muerte por hepatitis era mayor en Cerro Azul que en Varela, al igual que las personas con antecedente de ictericia y marcador de infección positivo. El porcentaje de mujeres con parto antes de los 20 años era alto en ambas poblaciones, siendo ligeramente mayor en Cerro Azul, sugiriendo una temprana iniciación sexual. Otras características halladas fueron: un número elevado de mujeres en Varela con más de un compañero sexual y el hecho de que la edad mediana de infección fuera tan diferente entre las dos poblaciones.

En Varela, el riesgo de estar infectado no se modifica con el sexo en el análisis crudo, pero al estratificar por edad observamos que en el grupo de edad de 15-24 años el riesgo se hace mayor entre los varones. (OR: 2,6 IC: $1.4,-7,4 \mathrm{p}=0,02$ ).

La disposición de excretas modificaba el riesgo de estar infectado en el análisis estratificado por edad, siendo dos veces mayor entre los que carecían de este servicio en su vivienda. (OR M-H: 2,2 IC: $1,3-3,7 \mathrm{p}=0.001$ ). La calidad de la vivienda (piso) y el hacinamiento, no se asociaron con un mayor riesgo de estar infectado por VHB, ni en el análisis crudo ni al estratificarla por otras variables.

Entre aquellos que manifestaron al menos un antecedente de ictericia, se aumentaba tres veces la probabilidad de estar infectado por VHB. (OR: 3,4 IC:1,0-30 p=0.03). El antecedente familiar de muerte por hepatitis, aumentaba dos veces el riesgo de estar infectado por VHB, rozando el límite de la significancia estadística.

Aquellas personas que se aplicaron cuatro o más inyecciones el año anterior, tenían un riesgo dos veces mayor de estar infectados, que los individuos que no se aplicaron inyecciones.(OR: 2.0 IC: 1.1$3.6 \mathrm{p}=0.03$ ). Las transfusiones de sangre en el hospital de Ciénaga, centro de atención del área, aumentaban tres veces el riesgo de estar infectado por VHB. (OR:3.0 IC:1.1-8.6 p=0.02).

TABLA 2

\section{DISTRIBUCION DE ALGUNOS FACTORES DE RIESGO EN VARELA Y CERRO AZUL}

\begin{tabular}{|c|c|c|c|}
\hline Factor de riesgo & Varela & $\begin{array}{l}\text { Cerro } \\
\text { Azul }\end{array}$ & $\mathbf{P}$ \\
\hline Población en hacinamiento & $25 \%$ & $19 \%$ & 0.04 \\
\hline \multicolumn{4}{|l|}{ Adultos con antecedente } \\
\hline de ETS & $0.4 \%$ & $2.8 \%$ & 0.001 \\
\hline \multicolumn{4}{|l|}{$\begin{array}{l}\text { Población con antecedente } \\
\text { familiar de muerte por }\end{array}$} \\
\hline hepatitis & $3.5 \%$ & $16 \%$ & 0.02 \\
\hline Edad mediana de infección & 28 años & 15 años & 0.03 \\
\hline \multicolumn{4}{|l|}{$\begin{array}{l}\text { Personas con antecedente de } \\
\text { ictericia y que están }\end{array}$} \\
\hline infectadas & $56 \%$ & $96 \%$ & 0.02 \\
\hline \multicolumn{4}{|l|}{ Madres con parto antes de } \\
\hline 20 años & $56 \%$ & $79 \%$ & 0.04 \\
\hline $\begin{array}{l}\text { Madres con más de un } \\
\text { compañero sexual }\end{array}$ & $27 \%$ & $9 \%$ & 0.02 \\
\hline
\end{tabular}


En Varela, el antecedente de enfermedades vénereas, el estado civil o el número de compañeros sexuales no modificaron el riesgo de estar infectado por VHB.

En Cerro Azul, las personas que habitaban casas con piso de cemento, sin disposición de excretas y en hacinamiento, tenían un riesgo de infección quince veces mayor que aquellos con viviendas en condiciones similares, pero sin hacinamiento. (OR:15 IC:3.4-75 p0.00006).

$\mathrm{El}$ antecedente personal de ictericia aumentaba seis veces el riesgo de estar infectado pero no alcanzaba significancia estadística.

El antecedente de alguna muerte por hepatitis dentro de la familia epidemiológica, aumentaba cinco veces el riesgo de estar infectado por VHB en las personas que lo referían. (OR: 5,0 IC: 1,1-34 $\mathrm{p}=0.03$ ). Al estratificar por edad el riesgo aumentaba once veces entre los que tenían positivo este antecedente. ( OR: 11,2 IC: 1,7- $66 \mathrm{p}=0.006$ ).

Las tablas 3 y 4 muestran la distribución de infectados para los factores hallados.

TABLA 3

FACTORES DE RIESGO AMBIENTAL

\begin{tabular}{lcccc}
\hline VARIABLE INF. NOINF. $\begin{array}{c}\text { M-H } \\
\text { OR }\end{array}$ & IC & p \\
\hline
\end{tabular}

Sin disposición

de excretas:

Edad

$\begin{array}{cccccc}0-4 \text { años } & 7 / 8 & 130 / 257 & & & \\ 5-14 \text { años } & 16 / 21 & 170 / 227 & & & \\ 15-44 \text { años } & 104 / 132 & 59 / 96 & & & \\ >44 \text { años } & 7 / 9 & 21 / 35 & 2.2 & 1.3-3: 7 & 0.001\end{array}$

\section{CERRO AZUL}

Hacinamiento*

3 o más personas

$\begin{array}{llllll}\text { porhabitación } & 54 / 71 & 3 / 17 & 15 & 3.4-74 & 0.0002\end{array}$

*Estratificado por piso de cemento y carencia de disposición de excretas.
TABLA 4

FACTORES DE RIESGO PERSONAL

\begin{tabular}{|c|c|c|c|c|c|c|}
\hline $\begin{array}{l}\text { Factor de } \\
\text { Riesgo }\end{array}$ & Inf. & Nolnf & $\begin{array}{c}\text { OR } \\
\text { Crudo }\end{array}$ & $\begin{array}{c}\mathrm{M}-\mathrm{H} \\
\text { OR }\end{array}$ & IC & p \\
\hline \multicolumn{7}{|c|}{ VARELA } \\
\hline Ictericia & $8 / 196$ & $6 / 490$ & 3.4 & & $1.0-30$ & 0.03 \\
\hline \multicolumn{7}{|l|}{ Transfusión en } \\
\hline Cienega & $5 / 196$ & $6 / 490$ & 3.0 & & $1.1-8.6$ & 0.02 \\
\hline \multicolumn{7}{|l|}{ Sexomasculino } \\
\hline 15-24 años & $26 / 54$ & $15 / 57$ & 2.6 & & $1.1-6.2$ & 0.02 \\
\hline \multicolumn{7}{|l|}{$\begin{array}{l}4 \text { o más inyeccio- } \\
\text { nes en el último }\end{array}$} \\
\hline año & $23 / 179$ & $31 / 444$ & 2.0 & & $1.1-3.6$ & 0.03 \\
\hline & & CERRO & AZUL & & & \\
\hline \multicolumn{7}{|l|}{$\begin{array}{l}\text { Antecedente } \\
\text { familiar de muer- }\end{array}$} \\
\hline te por hepatitis & $27 / 90$ & $2 / 26$ & 5.1 & & $1.1-3.4$ & 0.03 \\
\hline \multicolumn{7}{|l|}{ Estratificado } \\
\hline 0- 4 años & $5 / 10$ & $0 / 7$ & & & & \\
\hline 5-14 años & $5 / 21$ & $0 / 15$ & & & & \\
\hline $15-44$ años & $39 / 53$ & $2 / 4$ & 11.2 & $2.0-66$ & 0.006 & \\
\hline
\end{tabular}

\section{DISCUSION}

El patrón de infección por VHB difiere en ambas poblaciones. En Cerro Azul la exposición al VHB comienza desde muy temprana edad, siendo así que alrededor de los 15 años, el $50 \%$ de la población ya ha sido infectada con el virus, en tanto que en Varela, está alrededor de los 27 años.

La edad a la que se alcanza el pico de prevalencia varía según el tipo de transmisión involucrada. En países africanos y asiáticos, a la edad de 15 años ya el $50 \%$ de la población presenta marcadores de infección por VHB y un elevado porcentaje de personas con antigenemia $\mathrm{HBsAg}$ persistente, con el correspondiente peligro de cirrosis y hepatocarcinoma. Entre nosotros, el riesgo de que un portador 
desarrolle hepatitis fulminante, parece ser influenciado también, por la edad a la que se adquiere la infección por VHB. $(9,12,13,14,19)$.

El hecho de tener.hijos a menor edad en Cerro Azul, podría explicar parcialmente, la diferencia de prevalencia entre las poblaciones. Al ser adquirida la infección por VHB alrededor de la pubertad, hay menos probabilidad de neutralizar el $\mathrm{HBsAg}$ antes de los 20 años, lo cual hace posible que las madres menores de esa edad sean más infectantes para sus hijos. (9).

En Varela el sexo masculino está predispuesto a la infección por VHB en determinada edad de la vida; entre 15 y 24 años. Antes de esa edad, la probabilidad de estar infectado por VHB es igual para los dos sexos. Esta diferencia nos habla de un factor, probablemente actividad sexual, que no es igual para los dos sexos en este rango de edad. En otros estudios también se asocia al sexo masculino con una mayor probabilidad de infectarse, y de que la infección evolucione a un estado de portador crónico. $(9,13,14,15)$.

En la población de mayor endemicidad, Cerro Azul, no hay diferencia por sexo en la prevalencia de infección por VHB, ya que la infección se adquiere a muy temprana edad, la transmisión vertical y horizontal madre-niño y niño-niño por contacto estrecho, son las causas más probables de la infección, siendo estas fuentes de exposición comunes para ambos sexos.

En ambas poblaciones, el carecer de disposición de excretas se asoció con un mayor riesgo de estar infectado. El mecanismo por el cual ésta variable influiría en la transmisión del VHB no es claro, pero es una característica ligada a un bajo nivel socioeconómico. En Asia, algunos autores han encontrado disminución de la infección por VHB al mejorar la educación y las condiciones de vida. $(7,9,13)$.

El hacinamiento se asoció con una mayor probabilidad de estar infectado en la población de mayor prevalencia. Allí la cantidad de positivos para HBsAg es mayor, por lo que el hacinamiento favorece la diseminación intradomiciliaria del VHB. Se ha involucrado a la saliva, como un eficaz medio de transmisión del virus dentro del hogar, pero esta evidencia no es clara y se ha llegado a postular, que solo sería infectante cuando está mezclada con particulas de sangre. (8).

Otro mecanismo de transmisión intradomiciliaria postulado, es el intercambio de objetos de aseo personal; pero sólo los cepillos de dientes y las maquinas de afeitar, podrían ser un buen vehículo de transmisión del VHB, ya que son los que fácilmente se contaminan con sangre. (13).

Es importante el haber encontrado asociación entre transfusiones e infección por VHB, ya que esto debe obligar a que se doten los hospitales de la región, con los elementos necesarios para el tamizaje de los donantes. Esta asociación es hallada también en algunos países asiáticos. $(7,12,13)$.

La mayoría de los episodios de ictericia, son producidos por el VHB en ambas poblaciones, siendo esto significativamente mayor en Cerro Azul. Este hallazgo está de acuerdo con el de otros autores, que anotan más positividad al VHB cuando hay antecedentes clínicos de ictericia. (13).

Los contactos domiciliarios de personas fallecidas por Hepatitis Fulminante, tienen más probabilidad de estar infectados que aquellos sin éste antecedente familiar. Podemos sugerir que las personas fallecidas por hepatitis fulminante, han sido portadores del VHB por un tiempo tan largo, para haber actuado intradomiciliariamente, como transmisores eficientes del virus.

En otras poblaciones endémicas no se ha encontrado relación entre infección por VHB e inyecciones de medicamentos. En nuestro caso esta asociación podría ser causada por el hecho de que en Varela, hay dos personas que sin ningún entrenamiento, aplican inyecciones, haciéndolo con jeringas y agujas no desechables, cuya esterilización deja mucho que desear.

Con base en lo expuesto anteriormente, vemos que algunos mecanismos de transmisión difieren para las dos poblaciones. En Cerro Azul predomina un tipo de transmisión vertical y horizontal madrehijo; se da también la transmisión horizontal niñoniño, influenciada por factores ambientales y socioeconómicos, como el hacinamiento y la carencia de disposición de excretas. En Varela parece predominar la transmisión horizontal en una etapa más 
tardía de la vida, sugiriendo la intervención sexual, la cual ocurriría desde la pubertad hasta los $30-40$ años de edad.

Nuestros hallazgos coinciden con los de otros autores, que señalan como factores predisponentes al contacto por el VHB, el nivel socio-económico, el contacto intrafamiliar con un portador y la exposición a sangre y sus derivados. (9).

\section{SUMMARY}

During 1989 a seroprevalence survey on infection by HBV was performed in two villages in the Northern Colombia Coast in the Department of Magdalena: Cerro Azul and Varela which very recently have had cases of fulminant hepatitis caused by co - and superinfection by hepatitis Delta virus in carriers of $\mathrm{HBsAg}$.

According to the survey the results showed that among the population at the village of Cerro Azul, with the largest numer of cases of fulminant hepatitis, the hepatitis B virus infection starts in very early infancy, probably due to horizontal transmission and when they reach 15 years, half of them had been already infected by HBV. The principal factors associated to this infection were abscence of adequate excrete disposal, crowdness, and relatives dyeing of hepatitis.

The second village, Varela, less compromised by fulminant hepatitis, reveals a delayed onset of hepatitis B virus infection and from the age of 15 to 30 years, half of that population has adquired the infection by hepatitis B virus. Among them the factors associated are: inadequacy of excrete disposal, history of blood transfusions, parenteral pharmacological agents, and history of deaths by hepatitis among the epidemiological family.

\section{BIBLIOGRAFIA}

1. Ramsey G. Fever with jaundice inthe province of Santa Marta Colombia. Preliminar Report 1931. Presented to the International Division of the Rockefeller Foundation.

2. Bauer J, Kerr J. Una enfermedad pirética confundida con la Fiebre Amarilla en la costa Atlántica colombiana. Bol OPS 1933; 12:696.

3. Gast Galvis A. Hepatitis febril de Santa Marta. Salubridad 1955; 12:1145.
4. Buitrago B, Hadler S, et al. Epidemiology aspects of Santa Marta hepatitis over a 40 year. Hepatology 1986; 6:1292.

5. Deinhardt F, Gust D. Viral Hepatitis. Bull WHO 1982; 60: 661 .

6. OPS. Hepatitis B y Delta. Bol Epid OPS 1984; 5. (3) 7 . Davis G, Weber D. Horizontal transmision of Hepatitis B Virus. Lancet 1989; 1:406.

8. Sherlock S. The natural history of hepatitis B. Postgraduate Medical Journal 1987; 63 Supple 2:7.

9. Ganem D. Persistent infection of humans with hepatitis $B$ virus. Mechanisms and consecuences. Rev Inf Dis $1982 ; 4: 1026$.

10. Schlesseman J. Case and Control Studies. University Press. New York 1982.

11. Fox $E$, Abatte $E$, et al. Viral hepatitis marker in Djibouti: an epidemiological survey. TrRoy Soc Med Hyg 1988; 82:750.

12. Phoon $\mathbf{W}$, Fong $\mathbf{N}$, et al. History of blood transfution, tattoing, acupunture and risk of hepatitis B surface antigenemia among chinese men in Singapore. Am J Pub $\mathrm{H}$ 1988; $18: 958$.

13. Fonseca J, Simonetti S, et al. Prevalence of infection with hepatitis Delta virus among carriers of hepatitis B surface antigen in Amazonas State. Tr Roy Soc Med Hyg 1988; 82: 469.

14. Hu M, Schenzle D, et al. Epidemiology of hepatitis A and $B$ in the Shangai area. Prevalence of serum markers. Am J Epid 1984; 120: 404.

15. Heyward W, Bender T, et al. The control of hepatitis B virus infection with vaccine in Yupik Eskimos. Am J Epid $1984 ; 120: 650$.

16. Hadler S, Monzon M, et al. Delta virus infection and severe hepatitis. Ann Int Med 1984; 100:339.

17. The Gambia Hepatitis Study Group. Hepatitis B Vaccine in the expanded programme of inmunization: The Gambia experience. Lancet 1989; 1:1057.

18. Buitrago B, Martínez M, Hadler S, et al. Prevalencia de hepatitis $A, B, y$ Delta en Colombia. Encuesta en cuatro poblaciones de la zona bananera, departamento del Magdalena. The Hepatitis Delta Virus and its infection. pp 131-137. Alan R. Liss. Inc. New York 1987.

19. Maynard JE, Hadler SC, Fields HA. Delta Hepatitis in the Americas. An overview. The Hepatitis Delta virus and its infection. pp 121-128. Alan R. Liss. Inc. New York 1987.

20. Popper H, Buitrago B, Hadler SC, et al. Patology of Hepatitis Delta infection in the Amazon basin. The Hepatitis Delta virus and its infection. pp 121-128 Alan R. Liss. Inc. New York. 1987. 